\section{Creating Online Tutorials at Your Libraries}

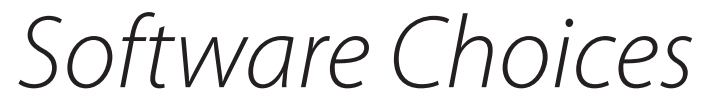

and Practical

Implications

As this is the last "Management" column I will be editing, some comments on the articles in this new column are in order. Three years has passed very quickly. During my tenure as column editor, I have looked for a variety of practical articles on how to improve reference services and increase opportunities to teach research strategies to our users. Because I am always looking for ways to gather data that can be used for management decisions, there have been two articles on survey tools. Another recent trend in reference service is to reach out to students where they are, so there have been two articles related to this: one on Web-based FAQs and another on embedded librarians. For this last column I have turned to colleagues at Purdue to discuss the new tutorials we are designing, again with the goal of reaching students when and where it is convenient for them.

Marianne Ryan, my colleague, will be the new editor of the column. She comes well qualified, as she has been associate dean of learning at Purdue and is now moving on to be associate university librarian for public services at Northwestern University.-Editor

\section{Maribeth Slebodnik and Catherine Fraser Riehle, Guest Columnists}

\author{
Correspondence concerning this \\ column should be addressed to Judith \\ M. Nixon, Head, Humanities, Social \\ Sciences \& Education Library, 504 W. \\ State St. STEW, Purdue University, West \\ Lafayette, IN 47907; e-mail:jnixon@ \\ purdue.edu.
}

\author{
Maribeth Slebodnik is Biomedical \\ Sciences Information Specialist \\ and Assistant Professor of Library \\ Science at Purdue University \\ Libraries. Catherine Fraser Riehle is \\ Instructional Outreach Librarian and \\ Assistant Professor of Library Science \\ at Purdue University Libraries.
}

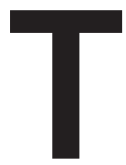

he use of online tutorials for information literacy instruction is on the rise. Active library-related discussion lists such as ILI-L, the Association of College and Research Libraries' discussion on information literacy and instruction, and LIBREF-L typically feature several questions and surveys related to online tutorials every week. Discussion groups and forums at library conferences consistently offer discussions, programs, and resources about creating online tutorials, and share examples.

What is causing the surge of interest in online tutorials? Reasons vary: staff shortages, a desire to provide more pointof-need assistance, and increased distance learning and a growing awareness-particularly in public and academic libraries-of the learning styles of the so-called Millennial Learner, who is said to prefer interactive, technology-based learning experiences. However, one of the main reasons for the trend is that the screen capture software available for tutorial construction has also grown increasingly capable and user-friendly. In this article we will review the software programs that are available, discuss the time and resources needed, and use a set of tutorials developed at Purdue for biology students as an example throughout.

\section{BACKGROUND AND CONTEXT}

Online tutorials provide some key advantages for libraries and library users. Particularly in libraries where in-person 


\section{MANAGEMENT}

instruction is not always feasible, online tutorials can reach more people than a typical instruction team. Tutorials can provide 24/7 access to library information as well as instruction in information literacy skills and electronic library resources. Routine training for a large population, such as for library orientation, is well suited for delivery via an online tutorial. Tutorials provide a focused demonstration that can be viewed at the learner's convenience, repeatedly if necessary; users only need an Internet connection and a Web browser with a media viewer, such as Flash, QuickTime, or Windows Media Viewer.

Though many would argue that in-person instruction cannot and should not be entirely replaced by online instruction, a research study by Silver and Nickel (2005) found online tutorials generally proved as effective as classroom instruction, that students' quiz scores and confidence levels were not statistically different depending on the type of instruction, and that the majority of students actually preferred online to classroom instruction. Should we as librarians abandon our traditions of in-person classroom instruction, entirely? Certainly not. Not only do our audiences and their learning styles differ, but there are some instructional opportunities-such as in-depth, course-integrated information literacy and research instruction-that may not be replaced by any current form of online instruction. For many skills and topics; however, the well-designed online tutorial can effectively provide instruction and assistance to a wide range of library users.

\section{WHAT SOFTWARE? HOW MUCH TIME AND RESOURCES? HOW EFFECTIVE ARE TUTORIALS?}

Before launching tutorials, library managers need to answer the following questions:

- How do we choose the most appropriate software for our purposes?

- What is the process for creating tutorials?

- What is the investment in time, resources, and training?

- How do we assess the tutorials' use and effectiveness?

\section{How Do We Choose the Most Appropriate Software for Our Purposes?}

\section{Feedback from Peer Institutions}

We surveyed eleven of our peer institutions-all comprehensive, land-grant, public research institutions with an intensive focus in science and technology. Although these institutions meet a specific set of criteria and characteristics, they are large institutions serving a variety of audiences, and we assume their responses will apply to a variety of librariesboth academic and otherwise. Of the eleven peer institutions contacted, six responded to the brief survey. Here are some of the key findings:
- The majority of responders ( 5 of 6 , or 80 percent) use Adobe Captivate and/or TechSmith Camtasia for creating online tutorials.

- Responders also used Articulate, SoftChalk, PHP, and Flash.

- The majority of responders (5 of 6 , or 80 percent) cited for "ease of use" and/or "features" in influencing their choice of software.

- Price and the availability of a PHP programmer were also cited as influential factors in choosing software.

- The majority of responders (4 of 6 , or 65 percent) assess tutorial use by automatically collecting use statistics.

- However, 2 of 6 (37 percent) responders did not collect use statistics.

- All responders (6 of 6, or 100 percent) conveyed that for the majority of their online tutorials, they felt the outcome was worth the investment in time and resources.

- Reasons cited included the ability to provide instruction to distance learners and the ability to reach out to more students in general.

Our preliminary survey results revealed that most respondents use either Captivate or Camtasia screen capture software, but other types of software were mentioned. We've assembled some basic information about the most frequently used screen capture software, including an open-access option for those working with restrictive budgets (see table 1). The table includes the basic capabilities of each software package. The ability to include quizzing is noted, as well as Sharable Content Object Reference Model (SCORM) compliance, which allows quiz results to be uploaded to a learning management system (LMS) for grading purposes. The ability to import Microsoft PowerPoint presentations is also noted, as is branching functionality for providing users with feedback when they answer a question incorrectly. All of the software companies offer academic pricing, which would typically be negotiated through a library's information technology department.

At Purdue, we have used both Camtasia and Captivate to develop tutorials. Captivate is currently supported by our IT department, which made it an easy choice for us. The IT department's adoption of Captivate was partially because of user requests for the software after it was initially released and partially because the academic pricing allowed us to buy multiple licenses. We would recommend either software package and encourage you to explore the software listed in the table to determine what works best for you and your institution. While we have focused on screen capture packages that use the Microsoft Windows platform, there are also numerous freeware, shareware, and retail options for Apple products.

Screen capture software not only enables video capture of screen activity but provides sophisticated editing capabilities to produce appealing online tutorials. Video files may be added to demonstrate noncomputing topics, such as science laboratory skills. Tutorials can be augmented with captions or callouts that emphasize key points. Music or narrative audio files may enhance learning and provide a deeper sense 
Table 1. Basic Capabilities of Software Packages

\begin{tabular}{|c|c|c|c|c|c|}
\hline & Camtasia Studio 6 & Captivate 4 & ScreenCorder 5 & Jing & $\begin{array}{c}\text { ViewletBuilder } \\
6 \text { Pro }\end{array}$ \\
\hline Audio capability & Yes & Yes & Yes & Yes & Yes \\
\hline Callouts/captions & Yes & Yes & Yes & Yes & Yes \\
\hline File output options & $\begin{array}{l}\text { AVI, animated GIF, } \\
\text { executable, Flash, } \\
\text { iPod video, MP3, } \\
\text { QuickTime, Real- } \\
\text { Media, WMV }\end{array}$ & AVI, Flash & $\begin{array}{l}\text { AVI, Flash, FLV, } \\
\text { WMV }\end{array}$ & Flash & Flash \\
\hline $\begin{array}{l}\text { Interactivity } \\
\text { (viewer can control } \\
\text { playback, take } \\
\text { surveys, etc.) }\end{array}$ & Yes & Yes & Yes & No & Yes \\
\hline Quizzing & Yes & Yes & Yes & No & Yes \\
\hline $\begin{array}{l}\text { SCORM compliance } \\
\text { (interacts with LMS } \\
\text { like Blackboard) }\end{array}$ & Yes & Yes & Yes & No & Yes \\
\hline PowerPoint import & Yes & Yes & No & No & No \\
\hline $\begin{array}{l}\text { Branching/ } \\
\text { looping for instant } \\
\text { feedback }\end{array}$ & Yes & Yes & Yes & No & Yes \\
\hline Software publisher & TechSmith & Adobe & MatchWare & TechSmith & Qarbon \\
\hline URL & www.techsmith.com & $\begin{array}{l}\text { www.adobe.com/ } \\
\text { products/captivate }\end{array}$ & $\begin{array}{c}\text { www.matchware } \\
\text {.com }\end{array}$ & $\begin{array}{c}\text { www.jingproject } \\
\text {.com }\end{array}$ & www.qarbon.com \\
\hline Distinctive features & $\begin{array}{l}\text { Will host videos at } \\
\text { Screencast.com }\end{array}$ & $\begin{array}{l}\text { Interactivity_can } \\
\text { use for quizzing, } \\
\text { etc. }\end{array}$ & $\begin{array}{l}\text { "... useful for non- } \\
\text { technical PC users," } \\
\text { can export } \\
\text { screenshots to } \\
\text { Microsoft Word }\end{array}$ & $\begin{array}{c}\text { "Capture, annotate, } \\
\text { share." No editing. } \\
\text { Fast visual } \\
\text { communication. }\end{array}$ & $\begin{array}{l}\text { Different versions } \\
\text { (Pro, Enterprise) } \\
\text { have different capa- } \\
\text { bilities. ViewletQuiz } \\
\text { for enhanced } \\
\text { quizzing options. }\end{array}$ \\
\hline Platform & Windows & Windows & Windows & $\begin{array}{l}\text { Windows, } \\
\text { Macintosh }\end{array}$ & Windows \\
\hline Cost & $\$ 299$ & $\begin{array}{c}\text { Full } \$ 799 \\
\text { Upgrade } \$ 299\end{array}$ & $\$ 249$ & $\begin{array}{c}\text { Free (Pro Version } \\
\quad \$ 14.95 / \mathrm{yr} \text { ) }\end{array}$ & $\$ 399$ \\
\hline Educational pricing & Yes & Yes & Yes & No (free) & Yes \\
\hline
\end{tabular}

of connection with the sometimes geographically distant instructor. Tutorials can be rapidly edited to reflect changes in a class, software package, or website without the need to completely redo the tutorial.

\section{What is the Process for Creating Tutorials?}

When developing online tutorials, it is useful to first define your motive for providing instruction and to develop clear learning objectives. This will help avoid wasting time and effort. Additionally, designing evaluation and assessment is much easier and more effective with clear goals and objectives in place.

For example, in the summer of 2008, one of the authors approached a professor of biological sciences who had developed a well regarded module to teach information and communication technology skills to beginning biology students. Because of curriculum changes, the module was no longer being taught, so we discussed alternative strategies for providing that information. The objective was to develop a series of tutorials that could be used in the first- and secondyear biology classes that would teach basic information literacy using biology-specific examples. Our third collaborator was an academic counselor in the biology department. We decided to use Captivate because we were familiar with it and had already found it to be useful. The series was based on Open Courseware tutorials from MIT, which we adapted using a Creative Commons license. Predetermining our model, our audience, our software, and our objectives made it much easier to write and construct the tutorials. 


\section{ONLINE TUTORIALS-SELECTED WEB RESOURCES}

Library Success Wiki. "Online Tutorials." www.libsuccess .org/index.php?title=Online_Tutorials (accessed Mar. 31, 2009). Links to tutorials, software information, blog posts, and articles.

Lib20. "Resources - Screencasting." http://lib20.pbwiki. com/resources-screencasting (accessed Mar. 31, 2009). Robust list of resources and tutorial examples.

American Library Association, Association of College and Research Libraries, Instruction Section. PeerReviewed Instructional Materials Online Database (PRIMO). www.ala.org/apps/primo/public/search. cfm (accessed Mar. 31, 2009). Excellent examples from academic institutions. Can be searched by "Creation Information" to find tutorials constructed with specific software.

Purdue University Libraries. "Tutorials for Biology Students Searching the Scientific Literature." http:// purl.lib.purdue.edu/web/biotutorials (accessed Mar. 31, 2009).

\section{Instructional Design: Length, Interactive Elements, Narration}

The best online tutorials are designed to organize information into small chunks that can be absorbed at a learner's own pace and allow the user to interact with the program by intermittent testing and feedback.

Usability testing at New York University revealed that users were not interested in committing time to lengthy tutorials - they wanted succinct information about how to use the library quickly. Some of the literature states that, optimally, tutorials should be two to three minutes long. It is also important to consider slow and fast modem connections and download times. Many users will not wait for a long tutorial to load. Also, minimize the number of plug-ins and other technical barriers so users do not get frustrated and stop. Several short and focused tutorials are better than one long, complex tutorial. This also eases the complexity of instructional planning and design, but it does not eliminate the need for careful design considerations altogether. When designing a series of intersecting or related tutorials, an overarching plan is essential for avoiding redundancy and missed elements. We were fortunate to use the model of the MIT Open Course Ware tutorials as a starting point for our own tutorial series, but we made modifications as we scripted the series to satisfy our own sense of the logical presentation order.

Including interactive elements should be considered early in the instructional design process. Most screen capture software allows for the inclusion of quizzes and other formal or informal testing, making interactivity easy to achieve. Interactivity also can be achieved by providing online exercises. An action as simple as clicking from screen to screen rather than passively watching the tutorial advance automatically can enhance interactivity and increase user attention.

In any scenario, it is useful to link wrong answers back to the correct information so that the learner can obtain instant feedback. Software with internal looping or branching options make this simple to achieve. For example, if a student chooses the incorrect answer for the following question, the feedback below the question is received:

Which statement most accurately describes the effect of Boolean AND and Boolean OR on database search results?

A. Boolean OR narrows, or decreases the number of search results, and Boolean AND broadens, or increases the number of search results.

B. Boolean AND narrows, or decreases the number of search results, and Boolean OR broadens, or increases the number of search results.

C. Boolean AND has no effect on the number of results, and Boolean OR narrows, or decreases the number of results.

Feedback: The correct choice was "B," Boolean AND narrows, or decreases the number of search results, and Boolean OR broadens, or increases the number of search results.

Emphasis of important points can be achieved through highlights, graphics, and other design elements that relieve the sense of "being lectured at" - which straight text blocks will produce-while retaining an uncluttered design. Likewise, internal navigation can enable learners to advance through the tutorial at their own pace and to return to review particular elements as needed.

Adding narration can really enhance tutorials and engage the learner. Narration requires careful planning and scripting but reinforces visual learning and can help to reach learners with different learning styles. Software that can provide "canned" voices will speed the process of narration by translating text into vocalization. Search online for "text to speech software" to purchase or find free examples of this type of application.

\section{Equipment}

To create online tutorials, computers with at least 8-10 GB of usable storage space, a streaming server account, and a software platform are required. If you intend to record audio for the tutorials, a microphone and quiet space or recording studio also will be needed. While headset microphones and simple handheld microphones can be purchased for around $\$ 25-50$ online or at most electronics stores, achieving quality 


\section{RECOMMENDED RESOURCES ON ONLINE TUTORIALS}

Bailin, Alan, and Aisha Pena. "Online Library Tutorials, Narratives, and Scripts." Journal of Academic Librarianship 33, no. 1 (2007): 106-17.

Clark, John D., and Kou Qinghua. "Electronic Resources Review: Captivate/Camtasia." Journal of the Medical Library Association 96, no. 1 (2008): 75-78.

Dewald, N., A. Scholz-Crane, A. Booth, and C. Levine."Information Literacy at a Distance: Instructional Design Issues." Journal of Academic Librarianship 26, no. 1 (2000): 33-44.

Dewald, Nancy H. "Web-Based Library Instruction: What Is Good Pedagogy?" Information Technology \& Libraries 18, no. 1 (1999): 26.

Ehrenberg, Ethan, and Nadaleen Tempelman-Kluit. "Library Instruction and Online Tutorials: Developing Best Practices for Streaming Desktop Video Capture." Feliciter 49, no. 2 (2003): 89-90.

Lindsay, Elizabeth Blakesley, Lara Cummings, Corey M. Johnson, and B. Jane Scales. "IfYou Build It, Will They Learn? Assessing Online Information Literacy Tutorials." College \& Research Libraries 67, no. 5 (2006): 429-45.

Silver, Susan L., and Lisa T. Nickel. "Are Online Tutorials Effective? A Comparison of Online and Classroom Library Instruction Methods." Research Strategies 20, no. 4 (2005): 389-96.

Smith, Susan Sharpless. Web-Based Instruction: A Guide for Libraries. 2nd ed. Chicago: ALA, 2006.

audio recordings in typical spaces can be a challenge. We invested in a quality microphone (\$100-150) with a microphone stand ( $\$ 50-100)$; you also can use a recording studio or space intended for audio recording if one is available. A quiet recording environment paired with high-quality equipment will make a world of difference in the tone and clarity of voice recording.

\section{Planning and Development}

We started with a storyboard that we based on transcripts of the MIT Open Courseware tutorials and recommend that you begin with a storyboard (or at least a rough outline) for your tutorial's content, especially for those that will include audio. A detailed script may not be necessary for short and simple tutorials. The script or storyboard will save recording and editing time and ensure that the tutorial content is carefully considered.

When planning the content, consider clarity, simplicity, and easy navigation. Eliminate possible points of confusion by cleaning up unclear terminology, dividing concepts and tasks into small achievable steps, and stating or displaying the navigation scheme at the beginning of the tutorial. Each tutorial should provide clear directions about how to proceed through the content. Again, we used transcriptions from the MIT Open Courseware tutorials as a starting point, and then wrote and edited scripts collaboratively in a freeware program called Celtx (http://celtx.com).

Next rehearse the process, narration, and any voiceover explanation that may be included. Take your time to get the narration right-it makes an important impression on your patrons. Record and produce the tutorial; then it is ready to be streamed to your library's server for public viewing. For many software platforms, the content will be converted to Flash or another format viewable by most personal computers.

\section{What is the Investment in Time, Resources, and Training?}

\section{Time Investment}

Creating online tutorials is time intensive. Libraries that have staff already trained in programming, audio recording and editing, and Web development will have key advantages. Depending on the level of expertise, even a short, three-tofive-minute tutorial with audio can take twenty or more hours to develop from start to finish. Is it worth the investment in time, effort, and possibly money? We think so, and according to our short survey, most librarians strongly agree. Online tutorials meet the needs of learners by providing access to instruction around the clock; they deliver consistent and timely instruction to a large group of incoming freshman or other populations such as large survey classes. These benefits outweigh the time needed for the development and maintenance of an online tutorial.

To support librarians and staff in this endeavor, consider offering a training session on relevant software, audio recording, and editing. College or university library personnel may find instructional design or software training opportunities offered by their campus IT or staff development departments. Faculty and staff across disciplines are using these technologies, so your campus may offer training and resources of which your staff can take advantage. Libraries can also purchase manuals, guides, and other materials to support staff in creating tutorials and to provide help when troubleshooting. Additionally, there is a wealth of information online-forums, Q\&A sites, tutorials, and more-to provide instruction and advice from within and outside the library community. 